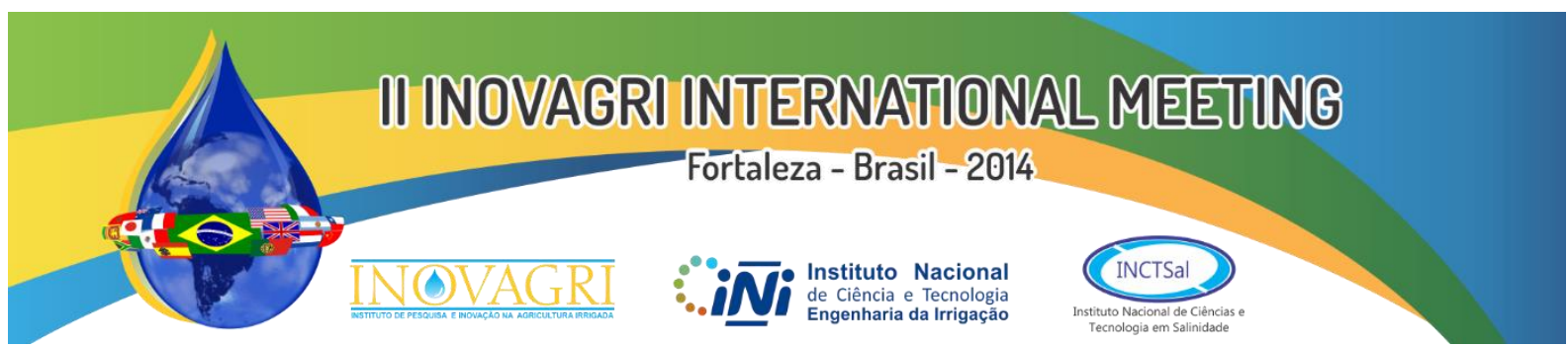

http://dx.doi.org/10.12702/ii.inovagri.2014-a701

\title{
PERDA DE ÁGUA E SEDIMENTOS EM DIFERENTES USOS DO SOLO
}

\section{F. A. Rieger ${ }^{1}$, C. A. Zolin², C. A. S. Magalhães ${ }^{3}$, J. Paulino ${ }^{4}$, A. L. Farias Neto ${ }^{5}$, J. L. P. Meneguci ${ }^{6}$}

RESUMO: No Brasil, um dos principais fatores de degradação dos solos é a erosão hídrica, amplificada na decorrência da interferência antrópica, por isso, a avaliação das perdas de solo nos processos de produção agrícola assume importância fundamental na escolha e adoção de práticas que visam minimizar sua degradação. Neste contexto o objetivo do trabalho foi avaliar o escoamento superficial, a perda de solo e as correlações entre o volume escoado superficialmente e o aporte de sedimentos em diferentes usos do solo. O presente estudo foi conduzido no campo experimental da Embrapa Agrossilvipastoril, município de Sinop (MT). Os tratamentos foram: a parcela com solo descoberto, parcela iLPF (integração lavoura, pecuária, floresta), com o componente arbóreo (eucalipto), parcela com eucalipto e parcela com lavoura (safra 2012/2013 com soja/milho). O solo foi classificado como Latossolo Vermelho Amarelo distrófico textura muito argilosa. O registro diário das chuvas ocorridas no período foi feito utilizando um pluviômetro digital e os valores obtidos foram utilizados na determinação do índice de Erosividade (EI30). Os dados de perda de sedimentos e água foram obtidos em parcelas de $132 \mathrm{~m}^{2}$, sendo $6 \mathrm{~m}$ de largura e $22 \mathrm{~m}$ de comprimento, delimitadas na parte superior e nas laterais por chapas galvanizadas munidas por calhas coletoras metálicas em seus limites inferiores. Para tanto, toda enxurrada escoada superficialmente era conduzida até a calha coletora, localizada na parte mais baixa da parcela, contando que as parcelas possuem declividade média de $1,5 \%$. Os sedimentos grosseiros foram coletados em sacos de algodão e a perda de solo foi a contabilização da massa seca dos sedimentos grosseiros com o solo em suspensão. Como resultados pode-se concluir que maiores perdas de água não resultaram necessariamente em maiores perda de solo; e com exceção do tratamento sem cobertura vegetal (SSC), todos os demais tratamentos apresentaram perdas de solo menores do que o limite de tolerância anual.

PALAVRAS-CHAVE: erosividade, iLPF, conservação da água

\section{WATER AND SOIL LOSSES UNDER DIFFERENT SOIL USE AND COVER}

SUMMARY: In Brazil, one of the mains factor driving soil degradation is water erosion, increased due to anthropogenic activities, therefore, the assessment of soil losses in agriculture activities play a crucial role for the decision making process regarding soil erosion. In this context, the goal of this work is to evaluate runoff and soil losses as well as their interaction into different soil use and cover. The study was carried out at the Embrapa Agrosilvopastoral researcher center, in Sinop, state of Mato Grosso. Four plots with average slope of $1.5 \%$ and different soil use and cover were evaluated, respectively a plot under bare soil, a plot under Integration of Crops, Livestock, and Forestry (iLPF), a plot under eucalyptus plantation and the last plot under crops (soybean and corn growing season). The soil of the experiments was classified as typic red Yellow Latosol. With the rain data during the study, measured using a automatically rain gauge, it was calculated the Erosivity Index (EI30). The plots dimension were $6 \mathrm{~m}$ wide and $22 \mathrm{~m}$ long, resulting in a total area of $132 \mathrm{~m}^{2}$, bounded on the top

\footnotetext{
${ }^{1}$ Mestrando, UFMT. Sinop - Mato Grosso. Email: feralerie@ gmail.com.

${ }^{2}$ Pós-doutorando, Pesquisador Embrapa Agrossilvipastoril. Sinop - Mato Grosso. Email: cornelio.zolin@embrapa.br.

${ }^{3}$ Doutor, Pesquisador Embrapa Agrossilvipastoril. Sinop - Mato Grosso. Email: ciro.magalhaes@embrapa.br

${ }^{4}$ Doutora, Professora UFMT. Sinop - Mato Grosso. Email: eng_janaina@ yahoo.com.br

${ }^{5}$ Doutor, Pesquisador Embrapa Agrossilvipastoril. Sinop - Mato Grosso. Email: chpd.cpamt@embrapa.br

${ }^{6}$ Doutor, Pesquisador Embrapa Agrossilvipastoril. Sinop - Mato Grosso. Email: joao.meneguci@embrapa.br
}
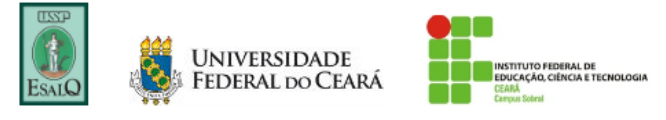
and sides with galvanized steel sheet and at the bottom part with a water and soil collector system where the runoff was transported for. The coarse sediments were collected in cotton bags and the total soil losses was achieved by the sum of coarse and suspended sediments. As a conclusion, except to the treatment without plant coverage, all treatments showed lower soil losses than annual limit of tolerance. Furthemore, high water losses was not necessarily related to great soil losses.

KEYWORDS: Erosivity, iLPF, water conservation.

\section{INTRODUÇÃO}

A erosão hídrica é um dos grandes problemas que ocasiona o empobrecimento dos solos brasileiros. A degradação do solo ocorre, de forma geral, pela interferência antrópica, devida a modificação das condições naturais (Silva et al., 2005), alterando a estrutura original do solo, favorecendo ao escoamento superficial e originando o carreamento de partículas que contribui no assoreamento dos corpos d'agua e no processo de eutrofização (Cruz, 2006).

A erosividade da chuva é descrita como uma interação entre a energia cinética e o momento do escoamento superficial (Santos et al., 2013). O índice de erosividade é função da intensidade e duração da precipitação, e da massa, diâmetro e velocidade da gota de chuva. Dos fatores responsáveis no processo, a capacidade da chuva em causar erosão, ou seja, sua erosividade é considerada como o fator mais ativo da erosão hídrica (Machado et al., 2008). Esse fator pode ser usado para definir em dada região qual a melhor época para estabelecer práticas de manejo e conservação de solo. Este fator pode servir ainda como parâmetro de suporte a trabalhos de extensão e assistência rural, pois permite definir épocas críticas quanto à ocorrência da erosão (Bertol,1994).

A avaliação das perdas de solo e água assume importância fundamental na escolha e adoção de práticas de manejo que visem minimizar a degradação do solo (Martins et al., 2003), sendo os sistemas de preparo plantio/semeadura de suma importância no controle da erosão. No sistema convencional a uma grande mobilização do solo, desestabilizando a estrutura e aumentando sua suscetibilidade a erosão. Por outro lado, o manejo da cobertura do solo proporcionada pelos resíduos culturais deixados na superfície tem ação direta e efetiva na redução da erosão hídrica, em virtude da dissipação de energia cinética das gotas da chuva, a qual diminui a desagregação das partículas de solo e o selamento superficial, aumentando a infiltração de água (Cogo et al., 2003).

No Brasil, embora exista ampla literatura sobre perda de água e solo, poucos são os estudos relacionados a esse tema em sistemas integrados. Adicionalmente, regiões e expansão agrícola, tais como a região de transição entre os biomas Amazônia e Cerrado no estado de Mato Grosso, carecem de melhor entendimento dos aspectos relacionados a perda de água e solo em diferentes configuração de uso e cobertura do solo de modo a buscar um uso mais sustentável desses recursos naturais.

Objetivou-se com a realização do presente trabalho estudar as perdas de água e solo, sob chuva natural, em diferentes configurações de uso e cobertura do solo, na região de transição entre os biomas Amazônia e Cerrado no estado de Mato Grosso.

\section{MATERIAL E MÉTODOS}

A pesquisa foi conduzida no campo experimental da Embrapa Agrossilvipastoril, no município

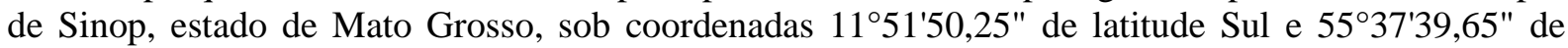
longitude Oeste, durante o período de outubro de 2012 a setembro de 2013. O clima da região, segundo a classificação de Köppen, é Aw (clima tropical de savana), com temperatura e precipitação média anual de $24,7{ }^{\circ} \mathrm{C}$ e $1974 \mathrm{~mm}^{2}$ ano $^{-1}$, respectivamente (Souza et al., 2013). O solo no local do experimento é classificado como Latossolo Vermelho Amarelo textura argilosa com horizonte A moderado. A declividade foi determinada em cada parcela experimental e amostras de solo foram coletadas nas áreas, para determinação da densidade nos tratamentos, além do teor de argila nos horizontes A e B, respectivamente.

As parcelas experimentais situam-se em uma área que foi por muito tempo explorada com lavoura, basicamente pelas culturas de soja, milho e algodão em plantio convencional. Com a saída da lavoura fez-se uma escarificação e gradagem na área para uniformizar a estrutura do solo. Após estas operações, que foram realizadas no final do ano de 2011, foram realizadas as atividades que se 
seguem, e que constituem os tratamentos empregados em cada parcela, sendo elas: PST - pastagem perene (Brachiaria Marandú), iLPF - sistema integração, lavoura, pecuária e floresta que continha apenas o componente arbóreo em consórcio com soja e milho, EPT - área com plantio de eucalipto clone (Eucalyptus urograndis h13), LVR - lavoura com sucessão soja e milho, SSC - solo sem cobertura vegetal e FTA - Floresta.

Os preparos do solo e a semeadura das culturas em linhas foram feitos no sentido perpendicular ao declive. $\mathrm{O}$ milho foi semeado em linhas espaçadas $0,50 \mathrm{~m}$ entre si, com distância entre plantas de $0,20 \mathrm{~m}$, a soja com espaçamento de $0,50 \mathrm{~m}$ entre linhas e 20 plantas por metro linear e a pastagem com $0,50 \mathrm{~m}$ entre linhas e 30 sementes por metro linear. O plantio de eucalipto foi feito com abertura de sulco (sulcador), espaçamento $3 \times 3 \mathrm{~m}$ com 1111 plantas ha $^{-1}$.

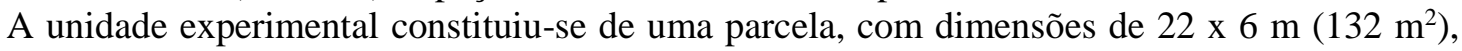
delimitada, superior e lateralmente, por chapas galvanizadas de $3,00 \times 0,30 \mathrm{~m}$ cravadas no solo em torno de $0,10 \mathrm{~m}$ e, na extremidade inferior, por uma calha coletora de enxurrada, a qual, através de um cano de PVC, conduzia a enxurrada a uma caixa de decantação interligada a outra caixa de armazenagem.

A caixa d'agua de armazenagem estava conectada à primeira por um divisor tipo "Geib", com 11 janelas, recebendo 1/11 da enxurrada excedente da primeira. Sendo assim a enxurrada (perda de água) foi determinada pela soma do volume coletado na primeira caixa e o volume da segunda caixa multiplicado por 11.

Os sedimentos grosseiros foram coletados através de sacos de tecido de $50 \mathrm{~L}$, instalados nas extremidades dos canos coletores, posteriormente foram colocados em estufa a $80^{\circ} \mathrm{C}$ até obterem massa constante. Os sedimentos em suspensão foram coletados após homogeneização da água dentro da caixa retirando uma alíquota de $1 \mathrm{~L}$, posteriormente foram levadas para o laboratório separando os sólidos da água com o auxilio do funil de Buchner com papel filtro (filtração lenta) com sucção de bomba vácuo e após a secagem do material, em estufa a $105^{\circ} \mathrm{C}$, determinou-se a massa de solo em suspensão contida na amostra, sendo extrapolado para o volume total de cada coleta de escoamento superficial. A soma dos sedimentos grosseiros e os de suspensão representou a perda de solo ocorrida na parcela.

No cálculo da erosividade foram utilizados dados pluviométricos mensais, obtidos em pluviômetro na área experimental, sendo a erosividade no período estudado (ano) considerada a soma da erosividade $\left(\mathrm{EI}_{30}\right)$ de cada mês.

Primeiramente calculou-se o coeficiente de chuva para cada mês $(\mathrm{Rc})$, pela seguinte relação:

$$
R c_{m}=\frac{P_{m}{ }^{2}}{P_{a}}
$$
(ano), $\mathrm{mm}$

em que $\mathrm{P}_{\mathrm{m}}$ é a precipitação do mês em questão, mm; e $\mathrm{P}_{\mathrm{a}}$ a precipitação ocorrida no período

Em seguida obteve-se a erosividade mensal $\left(\mathrm{EI}_{30 \mathrm{~m}}\right)$, de acordo com a equação proposta por Almeida et al. (2012), desenvolvida com os dados do município de Vera - MT, localizado próximo a região de estudo:

$$
E I_{30 m}=399,538719 \cdot R c_{m}{ }^{0,458718}
$$

Para fins de comparação, as perdas de solo foram ajustadas para o grau de declive (fator S) de $0,09 \mathrm{~m} \mathrm{~m}^{-1}$ da parcela padrão da Equação Universal de Perda de Solo Revisada em 1997, conforme proposto por McCool. Brown \& Foster (1987), por meio das seguinte equação:

$S=10,8 \operatorname{sen} \theta+0,03$

em que $\mathrm{S}$ é o fator grau do declive (adimensional); e $\theta$ o ângulo de declive do terreno.

Portanto, sendo o fator $\mathrm{S}$ a relação da perda de solo em uma parcela com declividade qualquer (PS) pela perda de solo na parcela padrão (PSP), a equação para correção ficou:

$$
P S P=\frac{1}{S} P S
$$

A tolerância de perda de solo por erosão hídrica foi calculada por meio da expressão utilizada por Lombardi Neto \& Bertoni (1975), embora se reconheça a fragilidade dos pressupostos utilizados no cálculo (Bertol \& Almeida, 2000), sendo:

$$
\mathrm{T}=\mathrm{h} \text { r } 1.000^{-1}
$$


em que T é a tolerância de perda de solo $\left(\mathrm{mm} \mathrm{ano}^{-1}\right)$; h a profundidade efetiva do solo $(\mathrm{mm})$, limitada a $1.000 \mathrm{~mm}$; e r o quociente que expressa o efeito da relação textural entre os horizontes B e A na ponderaçãodas perdas de solo $\left(\mathrm{g} \mathrm{kg}^{-1}\right)\left(\mathrm{g} \mathrm{kg}^{-1}\right)$.

\section{RESULTADOS E DISCUSSÃO}

A declividade encontrada na área de mata foi $0,03 \mathrm{~m} \mathrm{~m}^{-1} \mathrm{e}$ para os demais tratamentos $0,015 \mathrm{~m}$ $\mathrm{m}^{-1}$. As densidades encontradas nas áreas foram: $1,02 \mathrm{~g} \mathrm{~cm}^{-3}$ na FTA; $1,16 \mathrm{~g} \mathrm{~cm}^{-3}$ na iLPF; $1,17 \mathrm{~g} \mathrm{~cm}^{-3}$ no SSC e LVR; e $1,19 \mathrm{~g} \mathrm{~cm}^{-3}$ na PST e EPT.

A erosividade em MJ mm ha ${ }^{-1} \mathrm{~h}^{-1}$ mês juntamente com os dados de precipitação mensal coletados na área experimental no período de outubro de 2012 e setembro de 2013 e os dados médios mensais para a região (Souza et al. 2013), para comparação, constam na Figura 1.

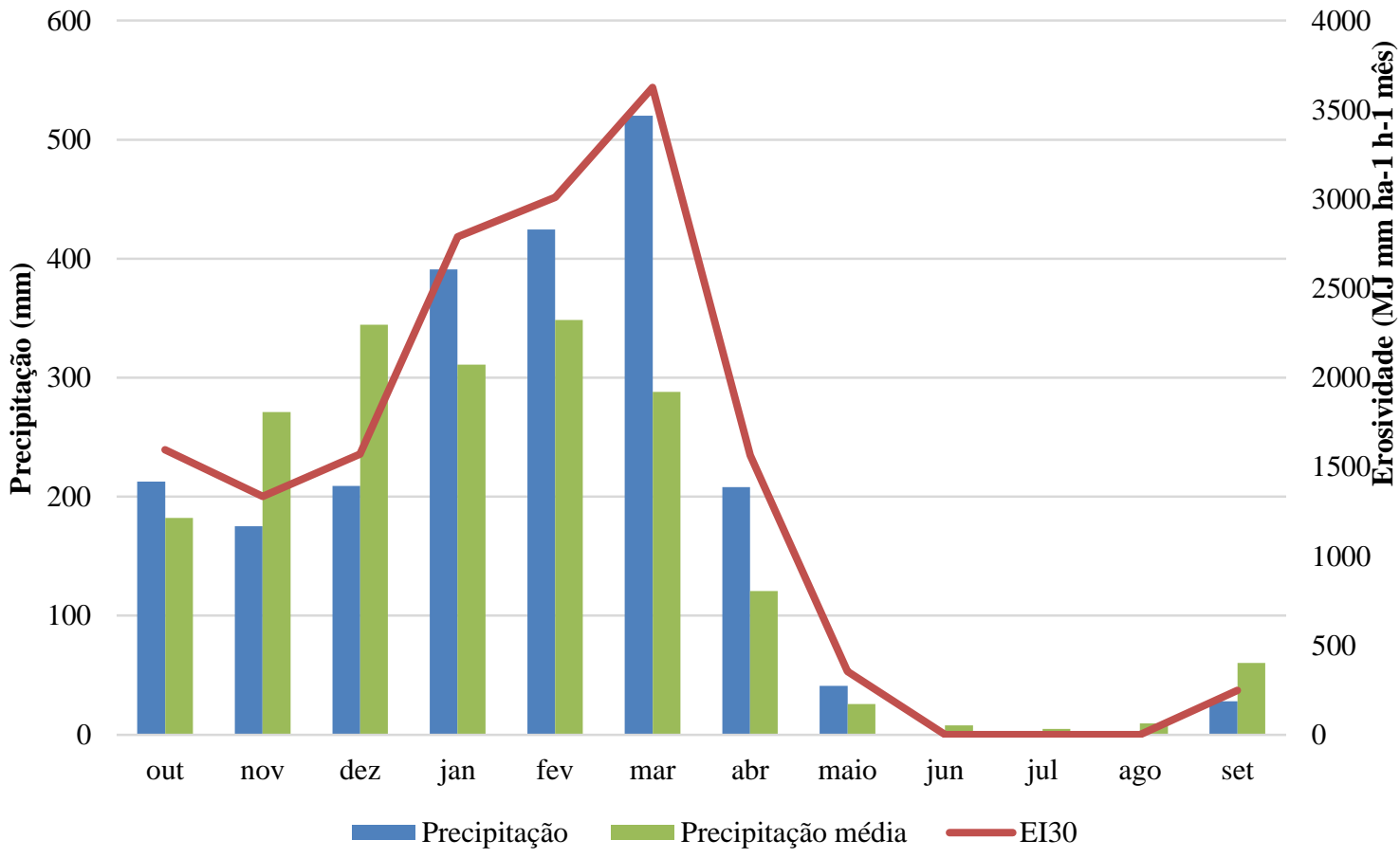

Figura 1. Precipitação pluvial e erosividade (EI30) mensal do período de outubro de 2012 a setembro de 2013

As perdas de água por escoamento superficial ocorridas entre o início do período chuvoso do ano de 2012 ao término do período das secas no ano de 2013 encontram-se apresentadas na Tabela 1. verifica-se que a precipitação total no período de estudo foi de $2209,67 \mathrm{~mm}$, sendo $596,72 \mathrm{~mm}$ no ano de 2012 e 1612,95 mm no ano de 2013, concentrando- se no período de janeiro a março de 2013.

O mesmo ocorre com a erosividade da chuva que teve os maiores picos nos meses de precipitação mais elevadas, apresentando valores de 2789,24 em janeiro; 3009,18 em fevereiro e 3624,89 $\mathrm{MJ} \mathrm{mm} \mathrm{ha}^{-1} \mathrm{~h}^{-1}$ em março, com total anual de 16091,73 $\mathrm{MJ} \mathrm{mm} \mathrm{ha}^{-1} \mathrm{~h}^{-1}$ ano. Almeida et al. (2012) estudando dados de erosividade da chuva em diferentes municípios do mato grosso, verificou no município de Vera valores de erosividade de $16220 \mathrm{MJ} \mathrm{mm} \mathrm{ha}^{-1} \mathrm{~h}^{-1}$ ano, valor este muito similar aos encontrados no presente estudo, o que demonstra o elevado potencial de erosividade da chuva para esses municípios nos meses de chuvas, evidenciando os cuidados que deve-se ter em manter a cobertura do solo para a redução do impacto das gotas da chuva e desagregação do solo.

Os valores de perda de água obtidos durante os meses de avaliação, seguem apresentados na Tabela 1. Verifica-se que estes variaram consideravelmente entre os tratamentos, sendo que o tratamento SSC apresentou valor de $675,3 \mathrm{~mm}$, o que representa perdas superiores, variando de $92 \%$ a $99 \%$, aos demais tratamentos. 
Tabela 1. Perdas mensais e total de água ocorridas entre o início do período das chuvas do ano 2012 ao ano de 2013, para os tratamentos avaliados

\begin{tabular}{|c|c|c|c|c|c|c|c|c|c|c|c|c|c|}
\hline \multirow[b]{2}{*}{ Mes } & \multicolumn{2}{|c|}{$\mathrm{SSC}^{(1)}$} & \multicolumn{2}{|c|}{$\mathrm{PST}^{(2)}$} & \multicolumn{2}{|c|}{$\operatorname{iLPF}^{(3)}$} & \multicolumn{2}{|c|}{$\mathrm{EPT}^{(4)}$} & \multicolumn{2}{|c|}{$\mathrm{LVR}^{(5)}$} & \multicolumn{2}{|c|}{ FTA $^{(6)}$} & \multirow{3}{*}{$\mathrm{P}^{(7)}(\mathrm{mm})$} \\
\hline & $\mathrm{mm}$ & $\%$ & $\mathrm{~mm}$ & $\%$ & $\mathrm{~mm}$ & $\%$ & $\mathrm{~mm}$ & $\%$ & $\mathrm{~mm}$ & $\%$ & $\mathrm{~mm}$ & $\%$ & \\
\hline \multicolumn{13}{|c|}{2012} & \\
\hline out & - & - & - & - & - & - & - & - & - & - & - & - & $212,56^{(8)}$ \\
\hline nov & 26,52 & 15,14 & 3,52 & 2,01 & 1,00 & 0,57 & 2,33 & 1,33 & 1,48 & 0,84 & 1,00 & 0,57 & 175,15 \\
\hline \multirow[t]{2}{*}{ dez } & 50,65 & 24,23 & 10,08 & 4,82 & 2,69 & 1,29 & 9,71 & 4,64 & 7,35 & 3,52 & 1,68 & 0,80 & 209,01 \\
\hline & \multicolumn{12}{|c|}{2013} & \\
\hline jan & 90,07 & 23,04 & 8,71 & 2,23 & 6,92 & 1,77 & 10,23 & 2,62 & 8,54 & 2,18 & 1,99 & 0,51 & 390,88 \\
\hline fev & 206,94 & 48,74 & 15,77 & 3,71 & 13,52 & 3,19 & 15,25 & 3,59 & 14,30 & 3,37 & 1,40 & 0,33 & 424,59 \\
\hline mar & 234,35 & 45,06 & 7,85 & 1,51 & 9,32 & 1,79 & 18,11 & 3,48 & 14,95 & 2,87 & 3,36 & 0,65 & 520,10 \\
\hline$a b r$ & 66,79 & 32,08 & 1,62 & 0,78 & 1,07 & 0,51 & 1,80 & 0,86 & 1,49 & 0,71 & 0,83 & 0,40 & 208,18 \\
\hline maio & 0,00 & 0,00 & 0,00 & 0,00 & 0,00 & 0,00 & 0,00 & 0,00 & 0,00 & 0,00 & 0,00 & 0,00 & 41,10 \\
\hline jun & 0,00 & 0,00 & 0,00 & 0,00 & 0,00 & 0,00 & 0,00 & 0,00 & 0,00 & 0,00 & 0,00 & 0,00 & 0,00 \\
\hline jul & 0,00 & 0,00 & 0,00 & 0,00 & 0,00 & 0,00 & 0,00 & 0,00 & 0,00 & 0,00 & 0,00 & 0,00 & 0,00 \\
\hline ago & 0,00 & 0,00 & 0,00 & 0,00 & 0,00 & 0,00 & 0,00 & 0,00 & 0,00 & 0,00 & 0,00 & 0,00 & 0,00 \\
\hline set & 0,00 & 0,00 & 0,00 & 0,00 & 0,00 & 0,00 & 0,00 & 0,00 & 0,00 & 0,00 & 0,00 & 0,00 & 28,09 \\
\hline Anual & 675,31 & 33,81 & 47,55 & 2,38 & 34,52 & 1,73 & 57,42 & 2,88 & 48,10 & 2,41 & 10,26 & 0,51 & 2209,67 \\
\hline
\end{tabular}

${ }^{(1)}$ SSC: solo descoberto. ${ }^{(2)} \mathrm{PST}$ : pastagem. $\cdot{ }^{(3)}$ iLPF: integração lavoura, pecuária, floresta; ${ }^{(4)} \mathrm{EPT}$ : eucalipto. ${ }^{(5)}$ LVR: lavoura. ${ }^{(6)}$ FTA: floresta. ${ }^{(7)}$ P: Precipitação. ${ }^{(8)}$ Valor não utilizado no cálculo da porcentagem de perdas anual.

Carvalho et al. (2007) encontraram o valor de $298 \mathrm{~mm}$ de perda de água em um Argissolo Vermelho-Amarelo desprovido de cobertura, no entando, o total precipitado foi de1429 $\mathrm{mm}$. Silva et al. (2005) encontraram valores de perdas anuais de água em solos descoberto de 371 e $114 \mathrm{~mm}$, respectivamente para um Cambissolo Háplico e Latossolo Vermelho. Pires et al. (2006) registraram perda de água de 85,61 mm em um Latossolo Vermelho-Amarelo desprovido de cobertura.

Para os demais tratamentos, com exceção do SSC, observam-se as maiores perdasde água para o tratamento com eucalipto (EPT), nos meses de janeiro a abril de 2013. Isso se deve possivelmente em função de o EPT estar no inicio do desenvolvimento, sem acumulo de serrapilheira que aumente a rugosidade da superfície e contribui para a diminuição do escoamento. Adicionalmente, o compontenete arbóreo (eucalipto) em sua fase inicial apresenta baixa interceptação pela copa, que aliado aos tratos culturais nas linhas podefavorecer o escoamento superficial.

Segundo Pires et al. (2006), no inicio do desenvolvimento à exposição do solo pela implantação intensificando as perdas de água, no plantio em nível de eucalipto encontrou valor de 77 mm de escoamento.

Com relação ao tratamento com pastagem (PST), verificou-se as maiores perdas nos meses de novembro e dezembro, o que pode ter ocorrido em função da retirada da maior parte da massa verde que se encontrava na parcela para aproveitamento de feno, antes da implantação da parcela. Logo após as primeiras chuvas a pastagem começou a se desenvolver novamente até a cobertura completa do solo. No início do mês de fevereiro foi efetuada roçagem da pastagem visando representar/simular o pastejo, uma vez que os animais ainda são se encontravam na área, o que diminuiu a cobertura. Adicionalmente, houve um aumento considerável na precipitação para o mês de fevereiro que aliado a redução da cobertura pela pastagem favoreceu o escoamento superficial.

Dentre os tratamentos, com exceção da área de floresta (FTA), a iLPF apresentou os menores valores de perdas de água, evidenciando a importância do componente arbóreo com a lavoura para a redução da energia cinética da chuva, favorecendo maior tempo de infiltração e redução do escoamento.

O tratamento com mata (FTA), como esperado, teve os menores valores de perda de água, variando entre 0,5 a $0,8 \%$ da precipitação total ocorrida no período de estudo, corroborando com 


\section{F. A. Rieger et al.}

Martins et al.(2003) e Brito et al.(2005). Tal resultado se deve ao efeito sinérgico da elevada capacidade de interceptação da floresta, acumulo considerável de restos vegetais e melhor estruturação do solo em função do sistema radicular das árvores e da atividade microbiológica. Esses fatores por sua vez exercem um papel fundamental na redução da energia cinética das chuvas e aumento da infiltração de água no solo.

Para o tratamento com lavoura (LVR) constatou-se perdas de água que variaram de 1,4 a 14,9 $\mathrm{mm}$, sendo os maiores valores observados no período de fevereiro e março, o que coincidiu com a colheita da soja e semeadura milho respectivamente, bem como com um período de alta erosividade da chuva. Cardoso et al.(2012) avaliando plantas de cobertura no controle das perdas de solo, água e nutrientes por erosão hídrica observou valores semelhantes de perdas de água para um Argissolo Vermelho-Amarelo em lavoura de Crotalária júncea.

Os valores de perdas de solo (PS) mensais seguem apresentados na Tabela3, onde se verifica que estes variaram entre 0,0002 a 5,5 $\mathrm{Mg} \mathrm{ha}^{-1}$, com a seguinte ordem crescente de perda de solos entre os tratamentos avaliados: floresta (FTA), pastagem (PST), eucalipto (EPT), lavoura, pecuária e floresta (iLPF), lavoura (LVR) e solo sem cobertura (SSC).

$\mathrm{Na}$ Tabela 2 encontram-se os valores mensais e total de perdas de solo ocorrida na declividade da área de cada tratamento e os valores ajustados para declividade $0,09 \mathrm{~m} \mathrm{~m}^{-1}$, de acordo com a Equação Universal de Perda de Solo revisada em 1997.

Tabela 2. Valores mensais e total de perdas de solo para a parcela de estudo(PS $)^{(1)}$ e ajustadas para a parcela padrão (PSP) ${ }^{(2)}$,em Latossolo Vermelho Amarelo

\begin{tabular}{|c|c|c|c|c|c|c|c|c|c|c|c|c|}
\hline \multirow{3}{*}{ Meses } & \multicolumn{2}{|c|}{$\mathrm{SSC}^{(3)}$} & \multicolumn{2}{|c|}{$\mathrm{PST}^{(4)}$} & \multicolumn{2}{|c|}{$\mathrm{iLPF}^{(5)}$} & \multicolumn{2}{|c|}{$\mathrm{EPT}^{(6)}$} & \multicolumn{2}{|c|}{$\operatorname{LVR}^{(7)}$} & \multicolumn{2}{|c|}{ FTA $^{(8)}$} \\
\hline & PS & PSP & PS & PSP & PS & PSP & PS & PSP & PS & PSP & PS & PSP \\
\hline & \multicolumn{12}{|c|}{$\mathrm{Mg} \mathrm{ha}^{-1}$} \\
\hline & \multicolumn{12}{|c|}{2012} \\
\hline out & - & - & - & - & - & - & - & - & - & - & - & - \\
\hline nov & 0.8983 & 4.6789 & 0.0125 & 0.0650 & 0.0513 & 0.2671 & 0.0996 & 0.5186 & 0.0961 & 0.5007 & 0.0050 & 0.0140 \\
\hline \multirow[t]{2}{*}{ dez } & 2.3872 & 12.4347 & 0.0274 & 0.1425 & 0.0979 & 0.5098 & 0.0187 & 0.0973 & 0.1038 & 0.5406 & 0.0037 & 0.0105 \\
\hline & \multicolumn{12}{|c|}{2013} \\
\hline jan & 4.2804 & 22.2960 & 0.0413 & 0.2151 & 0.0086 & 0.0447 & 0.0392 & 0.2042 & 0.0762 & 0.3967 & 0.0036 & 0.0102 \\
\hline fev & 5.5694 & 29.0100 & 0.0711 & 0.3706 & 0.0618 & 0.3217 & 0.0134 & 0.0697 & 0.3923 & 2.0434 & 0.0020 & 0.0056 \\
\hline mar & 2.8805 & 15.0039 & 0.0025 & 0.0132 & 0.0139 & 0.0725 & 0.0225 & 0.1170 & 0.1226 & 0.6388 & 0.0043 & 0.0123 \\
\hline$a b r$ & 0.8086 & 4.2117 & 0.0009 & 0.0045 & 0.0005 & 0.0025 & 0.0005 & 0.0025 & 0.0281 & 0.1463 & 0.0002 & 0.0007 \\
\hline maio & 0.0000 & 0.0000 & 0.0000 & 0.0000 & 0.0000 & 0.0000 & 0.0000 & 0.0000 & 0.0000 & 0.0000 & 0.0000 & 0.0000 \\
\hline jun & 0.0000 & 0.0000 & 0.0000 & 0.0000 & 0.0000 & 0.0000 & 0.0000 & 0.0000 & 0.0000 & 0.0000 & 0.0000 & 0.0000 \\
\hline jul & 0.0000 & 0.0000 & 0.0000 & 0.0000 & 0.0000 & 0.0000 & 0.0000 & 0.0000 & 0.0000 & 0.0000 & 0.0000 & 0.0000 \\
\hline ago & 0.0000 & 0.0000 & 0.0000 & 0.0000 & 0.0000 & 0.0000 & 0.0000 & 0.0000 & 0.0000 & 0.0000 & 0.0000 & 0.0000 \\
\hline set & 0.0000 & 0.0000 & 0.0000 & 0.0000 & 0.0000 & 0.0000 & 0.0000 & 0.0000 & 0.0000 & 0.0000 & 0.0000 & 0.0000 \\
\hline \multirow{3}{*}{ Anual } & 16.8243 & 87.6351 & 0.1557 & 0.8108 & 0.2339 & 1.2183 & 0.1938 & 1.0094 & 0.8191 & 4.2664 & 0.0188 & 0.0532 \\
\hline & \multicolumn{12}{|c|}{$\mathrm{mm}$} \\
\hline & 1.5577 & 8.1140 & 0.0141 & 0.0734 & 0.0218 & 0.1134 & 0.0176 & 0.0915 & 0.0753 & 0.3923 & 0.0020 & 0.0056 \\
\hline
\end{tabular}

${ }^{(1)}$ Perda de solo na área de estudo. ${ }^{(2)}$ Perda de solo considerando a declividade padrão de $0,09 \mathrm{~m} \mathrm{~m}^{-1}$.

${ }^{(3)}$ SSC: solo descoberto. ${ }^{(4)} \mathrm{PST}$ : pastagem. ${ }^{(5)} \mathrm{iLPF}$ : integração lavoura, pecuária, floresta; ${ }^{(6)} \mathrm{EPT}$ : eucalipto. ${ }^{(7)}$ LVR: lavoura. ${ }^{(8)}$ FTA: floresta.

Na Tabela 3 encontra-se a tolerância de perda de solo para as três amostras representativas coletadas na área experimental e os teores de argila nos horizontes A e B, utilizados para sua determinação. 
Tabela 3. Tolerância de perda de solo na área experimental e teor de argila nos horizontes A e B, para os pontos representativos da área total

\begin{tabular}{ccccc}
\hline \multirow{2}{*}{ Teor de argila } & \multicolumn{4}{c}{$\mathrm{g} \mathrm{kg}^{-1}$} \\
\cline { 2 - 4 } & $1^{(1)}$ & $2^{(1)}$ & $3^{(1)}$ & \\
\hline Horizonte A & 471.00 & 542.00 & 509.00 \\
Horizonte B & 574.00 & 564.50 & 551.50 \\
\hline $\mathrm{T}^{(2)}\left(\mathrm{mm} \mathrm{ano}^{-1}\right)$ & 1.22 & 1.04 & 1.08 & 1.08 \\
\hline${ }^{(1)}$ pontos amostrados na área experimental.
\end{tabular}

Verifica-se que a PS apresentou valores superiores para os tratamentos lavoura (LVR) e eucalipto (EPT) durante o mês de janeiro, o que se pode associar ao fato desses tratamentos ainda estarem na fase inicial de desenvolvimento, apresentando pouca cobertura sobre o solo.

Para o tratamento com lavoura (LVR) constata-se que as maiores PS ocorreram de dezembro a abril, sendo estas mais elevadas do que os demais tratamentos (com exceção do SSC), e isso se deve, possivelmente, ao fato da semeadura da soja e milho, deixando o solo com baixa cobertura nos períodos de maior precipitação e erosividade, favorecendo o impacto da gota da chuva sobre solo e causando o desprendimento e transporte de sedimentos. Analogia semelhante pode ser feita com o tratamento com pastagem (PST) que apresentou maiores valores de PS em janeiro e fevereiro em função da redução da cobertura do solo devido a roçagem para simular o pastejo. Já nos meses de março e abril observa-se diminuição da PS devido a pastagem ter retomado seu crescimento e aumentado a cobertura do solo.

Com relação ao tratamento iLPF observou-se PS relativamente baixa no mês de janeiro e alta no mês de fevereiro, o que ocorreu devido ao início da colheita da soja e posterior semeadura do milho. Com desenvolvimento da cultura nos meses que se seguiram verifica-se a diminuição da PS no referido tratamento.

No tratamento com eucalipto (EPT) verificou-se oscilações nas perdas de solo, com valores mais elevados no mês de janeiro e gradativa diminuição da PS ao longo do período estudado, o que é condizente com o desenvolvimento da cultura, pois essa passa a ter maior área de projeção das copas, apresentando maior interceptação da chuva e redução da energia cinética. Adicionalmente, com o desenvolvimento do eucalipto ocorre um aumento da presença de resíduos no solo, o que também contribui para redução do escoamento e transporte de sedimentos.

Para o tratamento com solo descoberto (SSC) as PS foram extremante superiores aos demais tratamentos, observando-se os maiores valores para os meses de alta precipitação. Beutler et al.(2003) avaliando perdas de solo e água num Latossolo Vermelho Alumino Férrico submetido a diferentes sistemas de preparo e cultivo sob chuva natural também observou valores semelhantes aos encontrados no presente trabalho.

Em relação às perdas de solo corrigidas para parcela padrão com declividade de $0,09 \mathrm{~m} \mathrm{~m}^{-1}, \mathrm{o}$ tratamento com SSC apresenta valor de $87,8 \mathrm{Mg} \mathrm{mm}^{-1} \mathrm{ha}^{-1}$, ou seja, 5,4 vezes mais em relação a condição do experimento. Nos demais tratamentos pode-se observar variações de 5,2 a 6 vezes em relação à condição do experimento. Comprovando a importância do fator declividade nas perdas de solo.

Com relação ao limite de tolerância de perda de solo, verifica-se que o tratamento SSC ficou acima do limite de tolerância que é de $1,08 \mathrm{~mm}$ ano $^{-1}$ ou de $10,8 \mathrm{Mg} \mathrm{ha}^{-1}$ ano $^{-1}$, sendo os demais tratamentos com valores inferiores ao limite de tolerânciapara perdas de solo do experimento. Quando corrigidos os valores considerado a parcela padrão com declividade de $0,09 \mathrm{~m} \mathrm{~m}^{-1}$, observa-se que somente o tratamento SSC continua com valores acima do limite de tolerância agora com $87,63 \mathrm{Mg}$ ha $^{-1}$ ano $^{-1}$, ou seja, 8 vezes acima do limite de tolerância. Esses dados enfatizam a importância da cobertura no solo e manutenção da mesma no decorrer dosmeses de precipitação. Carvalho et al. (2007) encontrou valores $18 \mathrm{Mg} \mathrm{ha}^{-1} \mathrm{ano}^{-1}$ em Latossolo Vermelho em parcela de solo descoberto, sendo o valor limite de tolerância de $12,70 \mathrm{Mg} \mathrm{ha}^{-1}$ ano $^{-1}$. Silva et al. (2005) obteve valores de perdas de solo $55,74 \mathrm{Mg} \mathrm{ha}^{-1}$ ano $^{-1}$ o qual esta acima do limite de tolerância. 


\section{CONCLUSÃO}

As perdas de solo e água no tratamento iLPF foram menores do que a do tratamento com lavoura (LVR), o que destaca a importância do componente arbóreo na redução das perdas.

A perda de solo variou de maneira decrescente do tratamento sem cobertura vegetal (SSC) à floresta (FTA) da seguinte maneira: SSC $>$ LVR $>$ iLPF $>$ EPT $>$ PST $>$ FTA.

A perda de água variou de menos de $1 \%$ (FTA) a mais de 33\% (SSC) do total de precipitação ocorrido no período avaliado e os demais tratamentos apresentaram as seguintes perdas em ordem decrescente: 2,88\% (EPT); 2,41\% (LVR); 2,38\% (PST); e 1,73\% (iLPF).

Maiores perdas de água não resultaram necessariamente em maiores perda de solo, o que indica que os fatores que favorecem as perdas de água nem sempre exercem a mesma influência sobre a perda de solo e que maiores enxurradas não necessariamente arrastam quantidades maiores de sedimentos.

\section{AGRADECIMENTOS}

Ao programa de pós graduação em Agronomia da Universidade Federal de Mato Grosso campus Sinop, à Embrapa Agrossilvipastoril e ao Conselho Nacional de Desenvolvimento Científico e Tecnológico CNPq.

\section{LITERATURA CITADA}

ALMEIDA, C.O.S.; AMORIM, R.S.S.; ELTZ, F.L.F.; COUTO, E.G.; JORDANI, A.A. Erosividade da chuva em municípios do Mato Grosso: distribuição sazonal e correlações com dados pluviométricos. Revista Brasileira de Engenharia Agrícola e Ambiental [online]. vol.16, n.2, pp. 142-152, 2012. http://dx.doi.org/10.1590/S1415-43662012000200003

BERTOL, I. Avaliação da erosividade da chuva na localidade de Campos Novos (SC) no período de 1981-1990. Pesquisa Agropecuaria Brasileira, v.29, n.9, p.1453-1458, 1994.

BERTOL, I.; ALMEIDA, J. A. Tolerância de perda de solo por erosão para os principais solos do estado de Santa Catarina. Revista Brasileira de Ciencia do Solo, 24:657-668, 2000.

BEUTLER, J. F.;BERTOL, I.;VEIGA, M. ;WILDNER, L. P..Perdas de solo e água num Latossolo Vermelho Aluminoférrico submetido a diferentes sistemas de preparo e cultivo sob chuva natural. Revista Brasileira de Ciencia do Solo, 27:509-517, 2003. http://dx.doi.org/10.1590/S010006832003000300012

BRITO, L. F.;PIRES, L. ; FERREIRA, M. S. M.; SILVA, M. L. N.; CURI, N.; LEITE, F. P. Erosão hídrica de latossolo vermelho muito argiloso relevo ondulado em área de pós-plantio de eucalipto no vale do rio doce, região centro leste do estado de minas gerais. Scientia Forestalis, n. 67, p.2736, abr. 2005.

CARDOSO, D. P.; SILVA, M. L. N.; CARVALHO, G. J.; FREITAS, D. A. F.; AVANZIJ. C. Plantas de cobertura no controle das perdas de solo, água e nutrientes por erosão hídrica. Revista Brasileira de Engenharia Agrícola e Ambiental, v.16, n.6, p.632-638, 2012. http://dx.doi.org/10.1590/S1415-43662012000600007

CARVALHO, R.; SILVA, M. L. N.; AVANZI, J. C.; CURI, N.; SOUZA, F. S. Erosão hídrica em latossolo Vermelho sob diversos sistemas de manejo do cafeeiro no sul de minas gerais. Ciência e Agrotecnologia, Lavras, v. 31, n. 6, p. 1679-1687, nov./dez., 2007.

COGO, N. P.; LEVIEN, R.; SCHWARZ, R. A. Perdas de solo e água por erosão hídrica influenciadas por métodos de preparo, classes de declive e níveis de fertilidade do solo. Revista Brasileira de Ciencia do Solo, Viçosa-MG, v. 27, n. 4, p. 743-753, 2003.

LOMBARDI NETO, F. \& BERTONI, J. Tolerância de perdas de terra para solos do estado de São Paulo. Campinas, Instituto Agronômico, 1975. 12p. (Boletim Técnico, 28).

MACHADO, R. L.; CARVALHO, D. F.; COSTA, J. R.; OLIVEIRA, D. H.; PINTO, M. F. Análise da erosividade das chuvas associada aos padrões de precipitação pluvial na região de Ribeirão das Lajes (RJ). Revista Brasileira de Ciencia do Solo, v.32, p.2113-1223, 2008. http://dx.doi.org/10.1590/S0100-06832008000500032 
MARTINS, S. G.; SILVA, M. L. N.; CURI, N.; FERREIRA, M. M.; FONSECA, S.; MARQUES, J. J. G. S. M. Perdas de solo e água por erosão hídrica em sistemas florestais nas regiões de Aracruz (ES). Revista Brasileira de Ciencia do Solo, Viçosa-MG, v. 27, p. 395-403, 2003.

MARTINS, S.G.; SILVA, M.L.N.; AVANZI, J.C.; CURI, N.; FONSECA, S. Fator cobertura e manejo do solo e perdas de solo e água em cultivo de eucalipto e em Mata Atlântica nos Tabuleiros Costeiros do estado do Espírito Santo. Scientia Forestalis., Piracicaba, v. 38, n. 87, p. 517-526, set. 2010.

MCCOOL, D. K.; BROWN, L. C.; FOSTER, G. R. Revised slope steepness factor for the Universal Soil Loss Equation. Transactions of the American Society of Agricultural Engineers, v. 30, p. 1387-1396, 1987. http://dx.doi.org/10.13031/2013.30576

PIRES, L. S.; BRITO, L. F.; SILVA, M. L. N.; CURI, N.; LEITE, F. P.Erosão hídrica pós-plantio em florestas de eucalipto na região centro-leste de Minas Gerais. Pesquisa Agropecuaria Brasileira, Brasília, v.41, n.4, p.687-695, abr. 2006. http://dx.doi.org/10.1590/S0100-204X2006000400021

SANTOS, M. A. N. Erosão hídrica em Argissolo Vermelho-Amarelo Distrófico submetido a diferentes sistemas de manejo. 2013. 65 p. Dissertação (Mestrado em Agronomia, Produção Vegetal) - Universidade Estadual de Mato Grosso do Sul, Aquidauana, 2013.

SILVA, A. M.; SILVA, M. L. N.; CURI, N.; LIMA, J. M.; AVANZI, J. C.; FERREIRA, M. M. Perdas de solo, água, nutrientes e carbono orgânico em Cambissolo e Latossolo sob chuva natural. P.A.B, Brasília, v. 40, n. 12, p. 1223-1230, 2005.

SOUZA, A. P.; MOTA, L. L.; ZAMADEI, T.; MARTIM, C.C.; ALMEIDA, F. T.; PAULINO, J. Classificação climática e balanço hídrico climatológico no estado de Mato Grosso. Nativa, Sinop, v. 01, n. 01, p.34-43, out./dez., 2013. 